\title{
"By The Way..." Phenomenon: A Qualitative Study of the Additional Demands in Closing Moments of Medical Interview in Family Medicine
}

\author{
Jose Luis Turabian*
}

Health Center Santa Maria de Benquerencia Toledo, Spain

\begin{abstract}
Objective: To identify and characterize, the additional demands (ADs) in the family medicine practice.

Participants and Methods: A qualitative, observational, narrative study, to explore the demand that occur at the end of the visit, with the presentation of a new query motif that is added to the previous one, once this one is finished, from June to August, 2017, in a family medicine office in Toledo, Spain, was carried out, by recording the words used by the patient. From a randomly selected date we included all patients performing additional demand until data saturation. An analysis of the content of the demands collected of each patient included was carried out. The technique to control bias was methodological triangulation between the results obtained with the data that had been reported in the literature.
\end{abstract}

Results: A total of 116 ADs were included, of which 85 (73\%) were from female patients and 31 (27\%) were from male patients. The age range was 14 to 91 years. The categories that were assessed as with very high or high importance were: 1) What seems to concern or interest the patient more in that moment or it seems to be the most important or the main reason for the doctor at that time, including the consultation on a chronic topic that presents itself as new; 2) What is related or insists in some way on the previous demand and expresses an action to act, or a fear of the previous demand; 3) to sleep or to "nerves"; 4) more than a demand is a story (usually psycho-social); and 5) demand for another family member present or absent in the consultation. The additional demand phrases that began with the conjunction "And ..." (In addition to) were the most frequent, followed by those that began with "And ... another thing ...", "Ah!" or "Oh!" (An interjection used to express surprise), and "And since I'm here ... "or" By the way ...".

Conclusions: Although some ADs seem to occur in a random manner and to be a superfluous request, most of them, however, can contain issues that most concern the patient or are rated as more important by the physician. ADs with some psychosocial content are the most frequent and important. But, its aspect of commonplace demands, make it difficult to take them into account. Family doctor never should underestimate any demand in closing moments of medical interview of the patient, especially if its content is partly psychosocial, since that may be the real and important motive that led him or her to the consultation. Therefore, a pragmatic, unstructured and strategic interview can be proposed: from where the doctor and the patient can go, in zigzag, "through the field instead of going the path", taking advantage of the opportunities, as the appearance of ADs.

Keywords: Family practice; Physician-patient relations; Visit to doctor's office; Communication; Closing moment's medical interview

\section{Introduction}

Communication is an important component of patient care and the cornerstone of general practice is the consultation. The clinical interview is a technique or channel and place of communication, where the doctor-patient relationship is produced and developed. Communication in the doctor-patient relationship points out (like signaling a path in the forest, so that we can focus our field study on the natural values of the place)-the clinical setting. Further, a systematic review of randomized clinical trials and analytic studies of physicianpatient communication confirmed a positive influence of quality communication on health outcomes $[1,2]$.

Michael Balint suggested that the patient begins the consultation by offering one or more problems and issues to the doctor. The doctor respond to these offers, indicating his acceptance or rejection of them, until some kind of compromise is worked out. In consequence, while the matters that are discussed in the consultation reflect the problems presented by the patient, they include only those aspects that the doctor indicates that are allowable [3]. Patients communicate their desires and expectations largely by making requests [4]. It has often been observed that patients present new concerns during the closing of the medical interview (hence the expressions 'doorknob concerns', and 'by the ways') [5].

The way a patient presents and exposes his health problem to the doctor determines in part the success or failure of the interview. The patient plans his meeting and elaborates a narration that in its most complete form consists, at least, of 2 parts: "business card", and exposition of facts and petitions (or expectations). The "business card" is the way to introduce yourself and the reason (or reasons) that brings you to the consultation. The request will usually be formulated at the beginning of the interview, but also it can be formulated at the end; these are the "additive requests" or "additional or additive demands" (ADs) which appear as the interview progresses, or at the end of

*Corresponding author: Jose Luis Turabian, Health Center Santa Maria de Benquerencia Toledo, Spain, Tel: 34925154508; E-mail: jturabianf@hotmail.com

Received November 22, 2017; Accepted November 25, 2017; Published November 27, 2017

Citation: Turabian JL (2017) "By The Way..." Phenomenon: A Qualitative Study of the Additional Demands in Closing Moments of Medical Interview in Family Medicine. J Gen Pract 5: 342. doi: 10.4172/2329-9126.1000342

Copyright: (c) 2017 Turabian JL. This is an open-access article distributed unde the terms of the Creative Commons Attribution License, which permits unrestricted use, distribution, and reproduction in any medium, provided the original author and source are credited. 
consultations with the introduction by the patient of a completely new set of symptoms. This is the popular "by the way... phenomenon." [6,7].

In the more than 1 billion primary-care visits each year in the United States, the majority of patients bring more than one distinct concern, yet many leave with "unmet" concerns (i.e., ones not addressed during visits). Unmet concerns have potentially negative consequences for patients' health, and may pose utilization-based financial burdens to health care systems if patients return to deal with such concerns [8].

Most health care professionals consider ADs as one of the main reasons that interfere with the normal course of the regular consultation. The $\mathrm{AD}$ produces a significant increase in the time of consultation and a decrease in the quality of care.

This situation is undoubtedly one of the most disturbing by the majority of the professionals who work in the field of primary care. When family doctor think that he or she has finished with a patient that is about to leave, but that returns to consult him or her a new symptom that forces to family doctor to restart the interview and even re-explore. This situation makes a very stressful feeling to professional, and it causes a great deal of exasperation to all doctors. It is common for the patient to use formulas such as "since I am here ..., "on purpose", "I also wanted to take advantage of ..... It is these situations that we know as AD ("by the way"). We can define them as that new query motif that is added to the previous one once this one is finished. It is, undoubtedly, a distorting factor of the assistance relation, they can alter the work routine and disorganize the limited consultation time available to the family doctor, as well as frequent source of errors, since in some occasion family doctor cannot give importance to the new demand, either for laziness of a new exploration, or think that as it is something that the patient says in passing and without giving it too much importance surely will not be anything important and common [9].

On the other hand, the $\mathrm{AD}$ are frequent or very frequent, being considered, overall, that between $15 \%$ and $40 \%$ of the visits carry some $\mathrm{AD}$ [10-12]. However, the studies carried out so far on this subject are scarce and deal rather with the repercussion of "By the way ..." in the dynamics of the query without trying to assess the importance or not of such $\mathrm{AD}$.

In this context, we perform a qualitative study whose objective is to identify and characterize the additional demands in the family medicine practice, cataloguing its typology according to the importance.

\section{Participants and Methods}

A qualitative, observational, narrative study, to explore the demand that occur at the end of the visit, with the presentation of a new query motif that is added to the previous one, once this one is finished, from 12 June to 12 August 2017, in a family medicine office in the Health Center Santa Maria de Benquerencia, Toledo, Spain, which has a list of 2,000 patients, was carried out, by recording the words used by the patient, and observing his or her kinaesthetic posture cues. Patients of both sexes over 14 years old were included (In Spain family doctors attend patients over 14-years-old),

Initially, as an operational definition, it was considered as additional or additive (AD), the demand that occurred at the end of the visit, with the presentation of a new query motif that is added to the previous one, once this one is finished [13], and that had not been announced previously (for example with the opening phrase of "Today I come for two things ..." or "Today I come for many things ..."). In the case of several additional demands, only the last of them was collected as an AD.
They were not considered $\mathrm{AD}$

- When the patient said from the beginning that he had several reasons

- The demands originated in the doctor when reviewing and updating chronic problems attended or preventive actions, etc.

- Urgent consultations

- When the patient was not present (such as anti-coagulated patients cited for International Normalized Ratio assessment in who did not make face-to-face consultations with the doctor)

- Home visits.

Closure phase of interview was defined of the medical visit as the final phase of the medical visit in which the doctor and patient shift perspective to the future, finalize plans, and say goodbye [14].

In the study, the doctor did not systematically ask the question "Anything else?" at the beginning of the interview, but did so only "according to art". Other variables collected were sex, age, and body movement of the patient (sitting, already about to come out of the consultation, or when the patient returns after he has left the room).

\section{Sample}

From a randomly selected date (June 12, 2017) all patients who underwent $\mathrm{AD}$ were included, until the saturation of the data, i.e. no new data were obtained [15]. The criterion of maximizing the diversity in obtaining the sample was taken into account, and all types of interviews were included, with the widest possible situations.

\section{Ethic aspects}

No ethical approval was required for the study as this was part of a normal service with registration of the reasons for consultation in the patient's medical records.

\section{Analysis}

An analysis of the content of the demands collected in the clinical records of each patient included was carried out, defining codes or categories of qualitative data, relating phrases sections with categories developed during the process of collecting narratives, and carrying out this process of organizing qualitative data using Microsoft ${ }^{\star}$ Word $[16,17]$.

\section{The process was as follows:}

- The written transcripts of the sentences of AD of the interviews were read by the researcher, and categories were assigned to each of them;

- A new reading of the sentences of the additional demands and their categories was made for each interview, re-assigning phrases of original data to new categories, and thus forming a file of definitive categories;

- The results were interpreted.

\section{Technique to control bias}

Methodological triangulation (it is to get different perspectives of the phenomenon studied). The triangulation was performed between the results obtained with the data that had been reported in the literature, which were compared with those obtained in the study 
Citation: Turabian JL (2017) "By The Way..." Phenomenon: A Qualitative Study of the Additional Demands in Closing Moments of Medical Interview in Family Medicine. J Gen Pract 5: 342. doi: 10.4172/2329-9126.1000342

Page 3 of 8

patients. In this way different perspectives of the studied phenomenon were obtained using different research methods.

A bibliographic search was carried out through electronic database Medline, internet search engines, and several in-house databases. It used key words like "Communication", "Physician-Patient Relations", "Patient Satisfaction", "Family medicine", and "Demand". In this search, no temporal limitation has been established, and only research on additional demands in family medicine has been taken into account. According to the method of non-systematic review, but narrative, there were no rules on how to get primary data, and how to integrate results. The subjective criterion of the reviewers was used. This narrative review did not intend to obtain quantitative synthesis of the data found in the different publications; Therefore, but obtain qualitative data that allowed to systematize and conceptualize the additional demands and use the results as technique to control bias of our study.

\section{Mind map}

Finally, a mental map was drawn, not only to arrange the results in graph form, but as a qualitative technique to understand the results in an integral or global way [18-20], using the free bubbl.us ${ }^{\circledR}$ online system [21].

\section{Results}

Total of 116 ADs were included, of which 85 (73\%) were from female patients, and 31 (27\%) were from male patients. The age range was 14 to 91 years. In many patients, there had no "additional demand" (AD), in the singular, but there had "additional demands" (ADs), in the plural, since in our study was more likely that patient to raise more than one unannounced demand at the beginning of the consultation. But, for this study, only the last demands were considered, although the patient had previously performed other unannounced demands at the beginning of the interview. Another result is no rare overlapping demands on the same patient with different characteristics or categories, such as request-demand and "shopping list".

When analyzing the additional demands, from the patients that made the number 80-90, the categories were repeated and did not appear new categories, although they were read and codified up to 116 additional demands of as many patients. The characteristics of the AD and the assessment of its importance in the judgment of the doctor are presented in Table 1 and Figure 1.

The categories that were assessed as very high or high importance were:

- What seems to concern or interest the patient more in that

\begin{tabular}{|c|c|c|c|}
\hline Categories of additional demands & Importance & Bio-psychosocial content & Examples \\
\hline $\begin{array}{l}\text { What seems to concern or interest more to } \\
\text { the patient at that moment or what appears } \\
\text { to be the most important or the main reason } \\
\text { for the physician at that moment, including } \\
\text { the consultation on a chronic theme that is } \\
\text { presents as new }\end{array}$ & Very high & Bio-psychosocial & $\begin{array}{l}\text { Example } 1 \text { (Woman of } 40 \text { years) .- "And another thing ... they touch me } \\
\text { and I start to cry ..." } \\
\text { Example } 2 \text { (Male of } 69 \text { years) .-"Well..., give me something for depressed } \\
\text { mood" } \\
\text { Example } 3 \text { (Male of } 63 \text { years).- "Ah! and the other day I had a moment of } \\
\text { lack of strength and numbness of the arm and the right leg that lasted me } \\
\text { a few minutes ... " }\end{array}$ \\
\hline $\begin{array}{l}\text { It is related in any form in the former demand } \\
\text { and expresses an action to act, or a fear of } \\
\text { the above demand, or it arise when a previous } \\
\text { request was denied }\end{array}$ & Very high-high & Bio-psychosocial & $\begin{array}{l}\text { Example } 1 \text { (21-year-old woman).- "I lost the appointment I had with the } \\
\text { gynecologist ... And another thing ... the rule is irregular ... although I will } \\
\text { tell this to the gynecologist ... } \\
\text { Example } 2 \text { (Woman of } 40 \text { years).- "And another thing: a few punctures in } \\
\text { the chest ... will not be anything? And a pain in the ribs ... It will really be } \\
\text { ribs, right?" } \\
\text { Example } 3 \text { ( } 51 \text {-year-old woman).- "I had two dizziness ... and my } \\
\text { eyes closed ... while driving, one time it was narrowed the road and } \\
\text { in the other believed to lose consciousness ... And I want to leave of } \\
\text { smoking..." }\end{array}$ \\
\hline To sleep or for "the nerves" & High & Psycho-social & $\begin{array}{l}\text { Example } 1 \text { (Male } 56 \text { years old).- "And finally a prescription of this (he } \\
\text { shows a container of bromazepam). I take it when I'm nervous or to sleep } \\
\ldots \text { now things are worse with my partner and ... " } \\
\text { Example } 2 \text { (52-years-old woman).- "Ah! and give me something to sleep } \\
\ldots \text { yesterday I did not sleep at all" } \\
\text { Example } 3 \text { (40-years-old woman).- "Ah! and must prescribe me the } \\
\text { lorazepam to sleep ... " }\end{array}$ \\
\hline $\begin{array}{l}\text { More than a demand is a history (generally of a } \\
\text { psycho-social character) }\end{array}$ & High-moderate & Psycho-social & $\begin{array}{l}\text { Example } 1 \text { (44-years-old woman).- "My father died and my mother } \\
\text { is with Alzheimer's ... but the separation has helped me ... I go to the } \\
\text { psychology ..." } \\
\text { Example } 2 \text { (66-years-old woman).- "Ah! and I'm going to tell you ... years } \\
\text { ago they threw the letters at me and told me things would be good for } \\
\text { me in the middle of my life, but I already spent half ... and I think about } \\
\text { death ..." } \\
\text { Example } 3 \text { (51-years-old woman).- "And a dentist deceived me ... who } \\
\text { pulled a tooth ... and now I will be an old woman without her teeth ..." }\end{array}$ \\
\hline $\begin{array}{l}\text { Demand for another family member present or } \\
\text { not in the consultation }\end{array}$ & Moderate-high & Psycho-social & $\begin{array}{l}\text { Example } 1 \text { (38-years-old woman) .- "And now my mother ... you have to } \\
\text { send her for the psychologist, again, because she laughs and cries ..." } \\
\text { Example } 2 \text { (69-years-old woman) .- "...And I'm going to tell you } \\
\text { something that my husband will not like ... he's very negative .... } \\
\text { and it's really worse ... Does not it seem to you? Need he to go to a } \\
\text { psychologist?" } \\
\text { Example } 3 \text { (Male 55).- "And now for me ... although I have no } \\
\text { appointment ..." }\end{array}$ \\
\hline $\begin{array}{l}\text { Requirement or petition (drug / test / referral } \\
\text {...), sometimes after a negative a prior request, } \\
\text { and including petitions which are considered } \\
\text { "normal" at the end of the consultation and } \\
\text { they are not part of the reason of visit (like a } \\
\text { drug for common use...) }\end{array}$ & Moderate & Biological & $\begin{array}{l}\text { Example } 1 \text { (51-years-old woman).- "Ah! and give me ibuprofen" } \\
\text { Example } 2 \text { (51-years-old woman).- "And .... do me an analysis" } \\
\text { Example } 3 \text { (34-years-old woman).- And ... since I am here, look at my } \\
\text { throat. }\end{array}$ \\
\hline
\end{tabular}


Citation: Turabian JL (2017) "By The Way..." Phenomenon: A Qualitative Study of the Additional Demands in Closing Moments of Medical Interview in Family Medicine. J Gen Pract 5: 342. doi: 10.4172/2329-9126.1000342

\begin{tabular}{|l|l|l|}
\hline & & $\begin{array}{l}\text { Example 1 (32-years-old male).- "And I have other things: A wart on the } \\
\text { leg ... Dandruff on the hair ... An itch in the scrotum for months ..." } \\
\text { Example 2 (31-years-old woman).- "My gut hurts ... I have low blood } \\
\text { pressure.... It was worse the facial dermatitis ... I gain too much weight " } \\
\text { Example 3 (31-years-old woman).- "The recipe of vitamins ...and iron .., } \\
\text { and a moisturizer and } \\
\text { acetaminofen to have it at home" }\end{array}$ \\
\hline $\begin{array}{l}\text { Additional demands type "shopping list" or "in } \\
\text { aterfall" }\end{array}$ & $\begin{array}{l}\text { Moderate-low } \\
\text { something, or to fill a vicious time, or a } \\
\text { prolonged silence, and that may appear as } \\
\text { without a lot of interest, to meet the established } \\
\text { behavior }\end{array}$ & $\begin{array}{l}\text { Example 1 (31-years-old woman).- "... And..., when I have to come to } \\
\text { picking up the document for continuation of work leave?" } \\
\text { Example 2 (Woman of } 36 \text { years) .- "And since I have finished with the } \\
\text { pregnancy ..., it does not matter..., but taking advantage ..., this lump of } \\
\text { the back ..." } \\
\text { Example 3 (41-years-old male) .- "And you know if the operations of } \\
\text { varicose veins have stopped ... I've been on the waiting list for more than } \\
1 \text { year ..." }\end{array}$ \\
\hline
\end{tabular}

Table 1: Types or categories of additional demands and their importance from the physician's viewpoint.

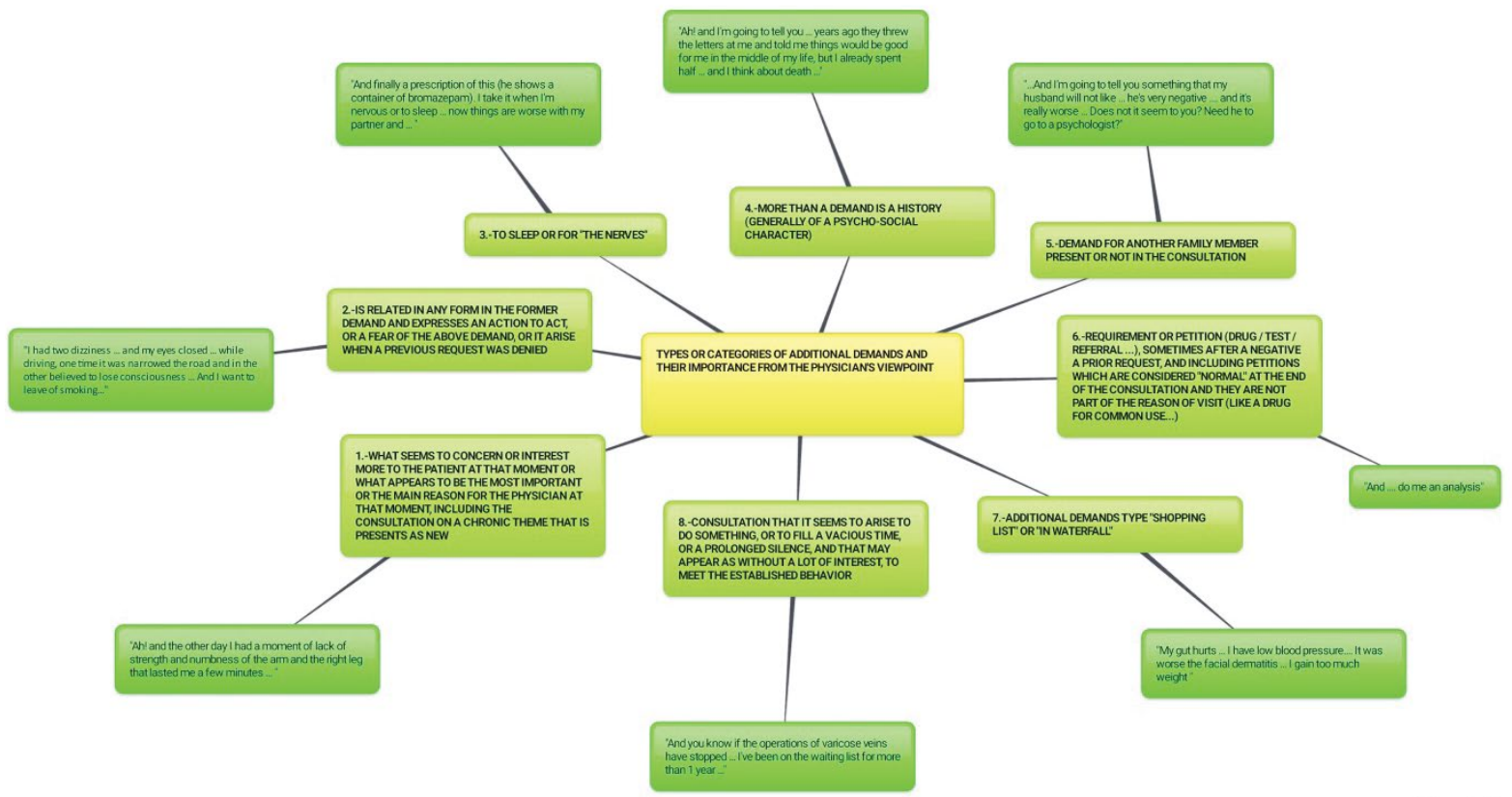

Figure 1: Types or categories of additional demands and examples.

moment or it seems to be the most important or the main reason for the doctor at that time, including the consultation on a chronic topic that presents itself as new;

- What is related or insists in some way on the previous demand and expresses an action to act, or a fear of the previous demand;

- To sleep or to "nerves";

- More than a demand is a story (usually psycho-social);

- Demand for another family member present or absent in the consultation (Figure 2).

Table 2 presents additional demand phrases. Those phrases that began with the conjunction "And ..." (In addition to) were the most frequent, followed by those that began with "And ... another thing ..., "Ah!" or "Oh!" (An interjection used to express surprise), "Ah! ..., and..., and "And since I'm here ... "or" By the way ..."

Table 3 presents the modalities of body movement when the AD was presented. Of course, sitting the patient in the office was the most frequent mode, but were not uncommon the presentations while the patient is already on the point of leaving the consultation, and even returning after leaving completely de room.

\section{Approach to a definition of additional demands}

With the data and characteristics obtained an approximation to the definition of AD was made. Additional Demand (AD) is the demand or consultation that occurs at the end of the visit and was not previously announced (for example with the opening phrase of "Today I come for two things ..." or "Today I come for many things ...”), which is usually preceded by a reflexive silence on the part of the patient, at the moment when the beginning of the farewell phrases was expected, or even the demand that occurs after the farewell, when the patient gets up from the chair to leave, or when he is opening the door to leave, or even after leaving the office, and he returning suddenly, and that usually anticipates with the phrases of "And..." (In addition to...). "And... another thing..." "Ah!" or "Oh!" (An interjection used to express surprise), "Since I'm here ..." or "By the way..." but also with "And I'm going to ask you a question ..., "And to what I come..., "And finally..., "And since I never come...", and "Well..." (Interjection; Tag in Spain).

$\mathrm{AD}$ frequently includes what seems to concern or interest the patient more at the time or seems to be the most important or the main reason for the doctor at that time, including consultation on a chronic topic that presents itself as new; Also, what is related in some way to the previous demand and expresses an action to act, or a fear of the previous 
Citation: Turabian JL (2017) "By The Way..." Phenomenon: A Qualitative Study of the Additional Demands in Closing Moments of Medical Interview in Family Medicine. J Gen Pract 5: 342. doi: 10.4172/2329-9126.1000342

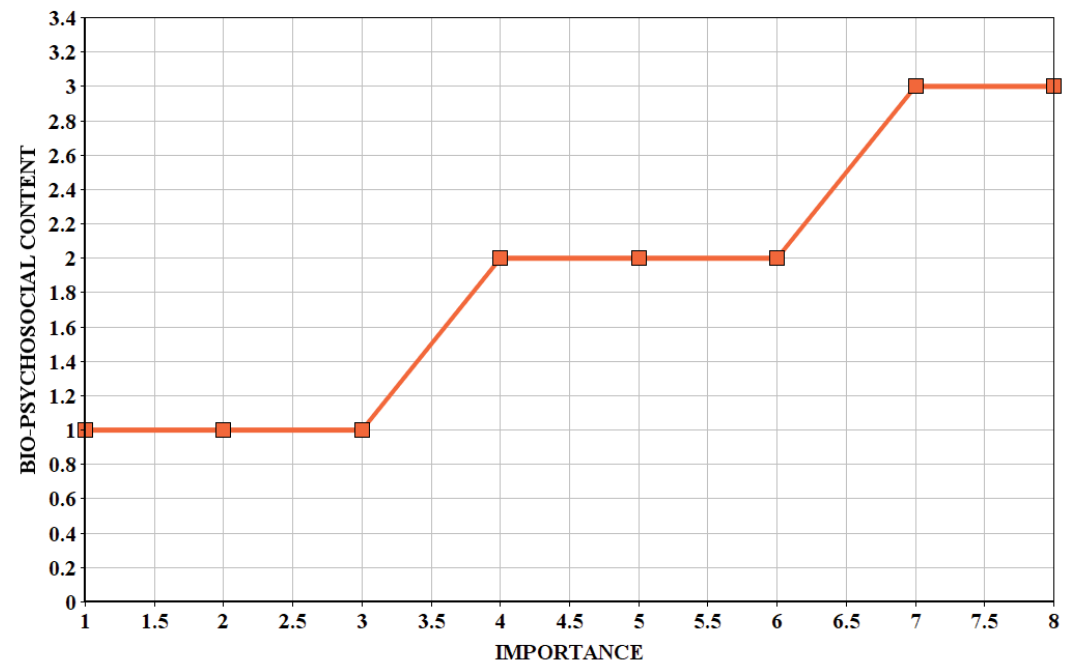

Figure 2: Shows the importance and bio-psychosocial content of the categories of additional demands. To construct the graph, a value of 8 was assigned to the first category and a value 1 was assigned to category 8 of Table 1.

\begin{tabular}{|c|c|}
\hline Starting phrases of additional demands & Examples \\
\hline $\begin{array}{l}\text { Very common start phrase (Conjunction "And": } \\
\text { In addition to) } \\
\text { "And..." }\end{array}$ & $\begin{array}{l}\text { "And the water gives me gas ..." } \\
\text { "And I noticed a lump in my neck" } \\
\text { "And ... I'm depressed .... my daughter left home that is already with her partner ... and since the death of my husband } \\
\text { I did not recreate my life ... and now alone ... I bought a small dog" } \\
\text { "And now my mother" } \\
\text { And.... you must do me an analysis } \\
\text { And I'm going to tell you ... I have a pain that goes away and comes in left side since January ... } \\
\text { And now for me ... although I have no appointment ... } \\
\text { And of the stomach ... I was in the Emergency Service last month and sometimes it happens to me.... } \\
\text { "And you have to prescribe me iron ... I'm very tired ..." } \\
\text { And my son's recipes } \\
\text { And look how I have eyes ... my eyelids itch }\end{array}$ \\
\hline $\begin{array}{l}\text { Very frequent start phrase } \\
\text { "And... another thing..." }\end{array}$ & $\begin{array}{l}\text { "And another thing .... I've got this crust out again..." } \\
\text { "And then another thing more important: many times I ejaculate very soon..." } \\
\text { "And another little thing ... I have not heard well since time ...." } \\
\text { "And another thing: In the summer I get heartburn with coffee with milk ... Do I try with milk without lactose?" } \\
\text { "And another thing a recipe of dexketoprofeno for when my head hurts ..." } \\
\text { "And another thing ... they touch me and I start to cry ..." } \\
\text { "And another thing: I hit the job at ..." } \\
\text { "And another thing ... this cream that the dermatologist prescribed me ..." } \\
\text { "And another thing ... urine smell me a lot at night ..." } \\
\text { "And another thing ... the dandruff shampoo is over ... with this bunch of hair" }\end{array}$ \\
\hline $\begin{array}{l}\text { Very common start phrase } \\
\text { "Ah!" or "Oh!" (An interjection used to express } \\
\text { surprise) "Ah! and..." }\end{array}$ & $\begin{array}{l}\text { "Oh, I'm on maternity leave for taking care of my brother's daughter ..." } \\
\text { "Ah! and the other day I had a moment of lack of strength and numbness of the arm and the right leg ..." } \\
\text { "Ah! and I'm going to tell you ... years ago they threw the letters at me and told me that things would be good for me in } \\
\text { the middle of my life, but I already spent half of it ... and I think about death ..." } \\
\text { "Ah! and you have to look at this ear that I hear nothing" } \\
\text { "Ah! and send me something to sleep .... yesterday I did not sleep at all" } \\
\text { "Ah! and you prescribe me ibuprofen that you did not prescribe the other day. } \\
\text { "Ah! and I want the stomach protector" } \\
\text { "Ah! and I want to remove these warts" } \\
\text { "Ah! and my knees hurt" }\end{array}$ \\
\hline $\begin{array}{l}\text { Frequent start phrase } \\
\text { "Ah! And since I'm here ..." or "By the way..." }\end{array}$ & $\begin{array}{l}\text { "Oh, by the way, prescribe me ibuprofen" } \\
\text { "And, since I'm here, you look at my throat" } \\
\text { "And, since I'm here ... I have these little spots ..." } \\
\text { "And, since I'm here ... my ears make me "gluglu" } \\
\text { "And, by the way, I have from a month a pain in the chest..." } \\
\text { "And, by the way, That you have to prick her with these kinds of needles ... You have to tell the nurse" }\end{array}$ \\
\hline $\begin{array}{l}\text { Little frequent start phrases } \\
\text { "And I'm going to ask you a question ..." } \\
\text { "And to what I come..." } \\
\text { "And finally..." } \\
\text { "And since I never come..." } \\
\text { "Well" (interjection; Tag in Spain) }\end{array}$ & $\begin{array}{l}\text { "And I'm going to ask a question ... for my diarrhea that there is..." } \\
\text { "And to what I come .... is for the eyes" } \\
\text { "And finally... a recipe of this ..." } \\
\text { "And since I have never come ... you prescribe me socks for varicose veins" } \\
\text { "Well..., give me something for depressed mood" }\end{array}$ \\
\hline
\end{tabular}

Table 2: Starting phrases of additional demands. 


\begin{tabular}{|l|l|}
\hline $\begin{array}{l}\text { Modalities of presentation of derived } \\
\text { demand }\end{array}$ & Examples \\
\hline $\begin{array}{l}\text { When the patient is sitting still in the } \\
\text { consultation (very frequent) }\end{array}$ & $\begin{array}{l}\text { - "And ... I have a very rare cough ..." } \\
\text {-"And my finger still hurts..." } \\
\text {--And... Can I take some pills that I have } \\
\text { "at home, for the dizziness?" }\end{array}$ \\
\hline $\begin{array}{l}\text { When the patient is already about } \\
\text { to come out of the consultation } \\
\text { (infrequent) }\end{array}$ & $\begin{array}{l}\text {-"Well..., give me something for } \\
\text { depressed mood" } \\
\text {-"And with my wife, you have to do } \\
\text { something ... She still get dizzy ..." } \\
\text {-Well... I'm tired and with hot flashes } \\
\ldots \text { to see if I take vacations ... I do not } \\
\text { know if I can with menopause ... }\end{array}$ \\
\hline $\begin{array}{l}\text { When the patient returns after he have } \\
\text { left the room (rare but not exceptional) }\end{array}$ & $\begin{array}{l}\text {-"And... My recipe of amoxicillin" } \\
\text {-"Oh, I'm on maternity leave for taking } \\
\text { care of my brother's daughter..." } \\
\text {-"And, by the way, That you have to } \\
\text { prick her with these kinds of needles ... } \\
\text { You have to tell the nurse" }\end{array}$ \\
\hline
\end{tabular}

Table 3: Modalities of presentation of derived demand.

demand. AD is often "to sleep or to nerves". Sometimes more than a lawsuit is presented at this time of closure of the interview a history (usually psycho-social). Likewise, the demand for another family member present or absent in the consultation is not uncommon, and the ADs that are demand or request (drug/test/referral ...), sometimes after a refusal to a previous request, and including requests, and that are considered "normal" at the end of the visit and are not part of the reason for visiting (a drug commonly used, or for the medicine cabinet at home ...). Lastly, there are also some ADs that seem to arise to fill an empty time, or a prolonged silence, without much interest, to comply with established behavior.

\section{Discussion}

\section{ADs with some psychosocial content are the most frequent and important}

The most frequent categories detected in our studio and those that are valued as of greater importance (What seems to concern or interest more to the patient or for the; A fear of the previous demand, or because of a previous request was denied; To sleep or for "the nerves"; Demand for another family member present or not in the consultation; And when more than a demand is a history) had mainly a major content psychosocial or bio-psychosocial. These data agree with those published, having reported that the content of $\mathrm{AD}$ was bio-psychosocial in $39 \%$, psychosocial in $36 \%$, or biomedical in $25 \%$. Therefore, those $\mathrm{AD}$ with some obvious psychosocial content, should alert the doctor, as they would indicate a major problem.

\section{Closing moments of medical interview}

Given what is known about the structure of institutional encounters such as medical interviews, it is perhaps not surprising that the closing phase offers opportunities for patients to express concerns for which they may not have found the place earlier in the consultation. This may be because of constraints of other tasks and activities, such as gathering information and physical examination, which tend to be led through the doctor's questions or actions. It may be because the closing offers reflective space and time for considering other, often unanticipated questions, problems and concerns from the patient's perspective. Or it may be that the patient has been hesitant to mention an issue of concern to them, in case it is not viewed by the doctor as medically legitimate or relevant.

Ideally, consultations should be concluded only when patient and doctor are both satisfied with what has been achieved. However, because doctors wish to keep to time and often terminate their interviews before the patient expect it, or because patients have their own individual awareness of how quickly time is passing, the ending the interview can have difficulties. The basis of these problems rest, partly, with the different expectations of doctor of patients. One of these problems which frequently occur at the end of consultations is the introduction by the patient of a completely new set of symptoms. This is "by the way...• phenomenon. It causes a great deal of exasperation to all doctors.

\section{"Oh, by the way doctor"}

The physician cannot assume that all of the patient's concerns will be raised early in the interview. Patients may talk about embarrassing or confidential problems when rapport and trust have been deepened. Not infrequently, the patient brings up important issues only at the end of the encounter by stating "Oh, by the way doctor" [22]. In our study, patients usually anticipate the ADs with the phrases of "And..." (In addition to), "And... another thing..., "Ah!" or "Oh!" (An interjection used to express surprise), "Since I’m here ..." or "By the way..." but also with "And I'm going to ask you a question ..., "And to what I come..., "And finally..., "And since I never come..., and "Well..." (Interjection; Tag in Spain). Of course, we must take into account the effects of the local context, so these phrases cannot be extrapolated to other contexts.

\section{Delimit demand and share the agenda}

The medical interview should be understood as an activity that integrates the family doctor's agenda (objective themes: diseases and risk factors) with the patient's agenda (subjective issues: Experience of the disease), trying to increase personal resources of general resistance against the disease [23]. The patient comes to the doctor with a narration, but also follows a pattern of conduct or script. By "delimiting the demand" is meant to clarify the reason for consultation. A high percentage of patients have more than one reason for consultation, so it is generally desirable to develop a demand map; this is to find out all the demands that the patient has prepared for this consultation.

Many family physicians were trained to focus visits on the patient's chief complaint. Some practices limit visits to a single issue or problem suggested by the patient, and others attempt to gather and address the patient's full list of concerns at each visit. It is assumed that physicians will also address important but unrelated issues such as abnormal laboratory results and age-appropriate screening as needed at any visit. But without a clear plan of what issues will be discussed and how they will be prioritized, encounters can become chaotic and not effectively meet the expectations of physicians or patients. Developing a shared agenda can help.

Sharing the agenda is straight-forward. After greeting the patient, the physician can ask open-ended questions to begin mapping the plan. Some physicians find it helpful to mention how much time they have [24].

\section{Is the patient with $\mathrm{AD}$ a difficult patient?}

A group of difficult patients are either those that have repetitive complaints, mainly without clear clinical significance, and strange unsolved complaints, or those who visit the doctor with multiple complaints-'a shopping list', or for whom 'everything hurts'. In these patients, the visits last a long time, usually much longer than the average, and the patients tire out their doctors [25]. Here, patients with ADs could enter as one more subgroup. However, our study suggests that the difficulty of $\mathrm{AD}$ can be seen as a great luck, as it allows us to access without too much work the main or most important problem. 


\section{Prevent additional demand. Is it possible, is it indicated?}

"By-the-way" syndrome, a new problem raised by the patient at an encounter's closure, is common, and it is mainly bio-psychosocial or psychosocial in content, but little is known about how physicians respond when it occurs, but has been communicated that the physician response is usually biomedical.

It has been proposed that to avoid "by the way..." phenomenon, patients should be encouraged at an early stage in the consultation to introduce all the problems they wish to discuss. Asking about the patient's agenda twice or more during the office visit might decrease the appearance of this syndrome.

But the question "Is there anything else?" is a way to prevent ADs? Not all authors agree. On the one hand, has been communicated that patients' unmet concerns can be dramatically reduced by a simple inquiry framed in the "some" form ("Is there something else you want to address in the visit today?"), instead of the "any" intervention ("Is there anything else you want to address in the visit today?") [26].

Set an agenda early in the visit helps avoid late-arising concerns that may be the most important issues to the patient ("by the way, I've been having these chest pains ..."). By not interrupting the patient's opening statement, and by using facilitating comments (also called "continuers," e.g., "is there anything else" or "uh-huh"), rather than immediately pursuing details of individual symptoms, the physician will have a better opportunity to discover the full range of patient concerns [27].

However, it has been reported that new problems occurred in $23 \%$ of visits, even those with open-ended beginnings and early physician requests for all patient concerns. And other authors state that by asking the question: "Is there anything else?" not only is it not prevented, but a higher percentage of ADs occurs, or identifying the patients' agenda (Patients allocated to ask to complete a patient's agenda form when they arrived for their consultations, or not), the occurrence of "by the way" presentations did not change [28]. Moreover, it is very frequent the presence of multimorbidity that can give rise to many demands during the consultation. About half the patients at general practitioner encounters had two or more diagnosed chronic conditions and over one third had three or more [29].

Therefore, the main conclusion could be that the intervention with "wanted something more?" Does not increase the ADs, but it does make explicit the DA at the optimum moment, from the organizational point of view, for the professional. Furthermore, when they are allowed to participate more actively they are less likely to withhold important information. If, however, an additional problem does arise unexpectedly in this way, it is obvious that the patient must have been reluctant to talk about it previously. So it is important not to discourage him as it is likely to be a major concern. It put off, particularly in a manner that the patient might consider brusque; the opportunity to talk about it may be lost permanently.

Some ADs can occur as a form of distraction with further random questions. Perhaps surprisingly, some doctors, or in same situations during the consultations-because of use of computer, fill forms, etc.have difficulty in terminating their consultations, and so, patient and doctor could distract themselves with further random questions, or topics which should have been previously covered. On the other hand, the type of additive consultation in pediatrics is usually banal.

In our study, including patients from 14 years of age, there is a small number of ADs that seems to occur "to do something, or to fill a vicious time, or a prolonged silence, and that may appear without a lot of interest, to meet the established behavior", and another small number of AD type "shopping list" or "in waterfall", of low importance.

\section{The endings may be contained in the principles}

Despite our efforts, $30-80 \%$ of our patients' expectations are not detected [30]. In addition, the structuring of the clinical encounter may be adequate, but its usefulness is limited by the lack of flexibility [31]. On the other hand, half of the doctors redirected the initial discourse of the patient very early on (in 16 seconds) and this are significantly associated with new concerns by the patient at the time of closing and with longer goodbyes [32]. When patients visit primary-care physicians, they frequently have more than one concern. Patients' first concerns are solicited by physicians at the beginnings of encounters. A challenge to health care is how to get patients' additional concerns raised as topics of discussion. If patients' additional concerns are addressed, it tends to occur at the end of encounters [33].

New problems in closure were associated with less information exchanged previously by physicians and patients about therapy, fewer orientation statements by physicians. Long closures ( $>2$ minutes) correlated with physicians' asking open-ended questions, and engaging in psychosocial discussion with patients [34]. ADs are not presented completely unexpectedly or randomly as commonsense understanding sometimes has it; they are introduced at orderly moments and by means of recognizable methods [35]. Therefore, a pragmatic, unstructured and strategic interview can be proposed: from where the doctor and the patient can go, in zigzag, "through the field instead the path", taking advantage of the opportunities, as the appearance of ADs.

\section{Limitations of the Study}

- The interviews were not video or audio recorded, but the data were memorized and written in the medical history of each patient immediately after each interview. This introduces the possibility of some mistake of remembering the sentences.

- The concept and presence of AD probably depends on the cultural contexts and health care (organization, accessibility, etc.) so our work refers only to an type of organization of Western European countries where around two-thirds of any population consults in a family medicine service at least once a year, and more than $80 \%$ contact once every 5 years, all people are registered in a general practice and the general practitioner is the gatekeeper of health care [36-39], and may not be comparable to the understanding of closings in the primary-care interview in a non-western setting [40].

\section{Conclusion}

$\mathrm{AD}$ is an external, perhaps minimal, sign or clue that may reflect internal signs of the patient's feelings and thoughts, along with others admitted, such as what the patient says, the vocabulary, the metaphors, the rhythm, the tone and voice volume, facial expression, posture, etc. It is probably a "language" of the patient that we must take into account [41]. Although some ADs seem to occur in a random manner and to be a superfluous request, this idea ignores a lot of information (clinical and emotional) of great importance, and leads to a failure to understand the demand for help that meant $\mathrm{AD}$, and to value that signal as an exponent of a problem. Most of ADs can contain issues that most concern the patient or are rated as more important by the physician. ADs with some psychosocial content are the most frequent and important. But, its aspect of commonplace demands, make it difficult to take them into account. Family doctor never should underestimate any demand in 
Citation: Turabian JL (2017) "By The Way..." Phenomenon: A Qualitative Study of the Additional Demands in Closing Moments of Medical Interview in Family Medicine. J Gen Pract 5: 342. doi: 10.4172/2329-9126.1000342

closing moments of medical interview of the patient, especially if its content is partly psychosocial, since that may be the real and important motive that led him or her to the consultation. Consequently, no patient's demand should ever be underestimated, since that may be the real reason for the consultation. A pragmatic, unstructured and strategic interview can be proposed: from where the doctor and the patient can go, in zigzag, "through the field instead the path", taking advantage of the opportunities, as the appearance of ADs.

\section{References}

1. Teutsch C (2003) Patient-doctor communication. Med Clin North Am 87: 11151145.

2. Turabian JL, Perez Franco B (2008) The effect of seeing the sea for the first time. An attempt at defining the family medicine law: The interview is clinical medicine. Aten Primaria 40: 565-566.

3. Usherwood T (2009) Understanding the consultation. Evidence, theory and pactice. Open University Press, Berkshire, UK

4. Kravitz RL, Bell RA, Azari R, Krupat E, Kelly-Reif S, et al. (2002) Request fulfillment in office practice: Antecedents and relationship to outcomes. Med Care 40: 38-51.

5. UK Council of clinical communication

6. Carrió BF, Clemente JC, Lázaro J (2011) Demands and complaints in the clinical interview, key concepts for a safer clinical practice. Med Clin 137: 216 220.

7. Livesy PG (1986) Partners in care. The consultation in General Practice. William Heinemann Medical Books, London.

8. Robinson, JD, Heritage J (2016) How patients understand physicians solicitations of additional concerns: Implications for up-front agenda setting in primary care. Health Commun 31 (4): 434-444

9. Fuentes J (2000) Additional demands. FMC 7: 464-465

10. Fernánde PC, Rodríguez MI, Gil SP, Malo de Molina Martínez A, Díaz Álvarez (1996) Additional requests ("seeing that...") in primary care. Aten Primaria 17 $13-17$

11. Segade Buceta XM, Sánchez Santos L, Losada Pazo MC, Méndez Bustelo MJ, Blanco-Ons Fernández MP (2009) Additive demands in Primary Care Pediatrics. A multicentre study. Rev Pediatr Aten Primaria 11: 233-239.

12. Rodondi PY, Maillefer J, Suardi F, Rodondi N, Cornuz J, et al. (2009) Physician response to "by-the-way" syndrome in primary care. J Gen Intern Med 24: 739-741.

13. http://comunicacionysalud.es/wp-content/uploads/2014/08/ EntrevistaClinica_2004.pdf

14. White JC, Rosson C, Christensen J, Hart R, Levinson W (1997) Wrapping things up: A qualitative analysis of the closing moments of the medical visit. Patient Educ Couns 30: 155-165.

15. Bell J (1997) Doing your research project. A guide for first-time researches in education and social sciences. Open University Press, Buckingham, UK

16. Bowling A (2000) Research methods in health. Investigating health and health services. Open University Press, UK.

17. Burnard P, Gill P, Stewart K, Treasure E, Chadwick B (2008) Analysing and presenting qualitative data. Br Dental J 204: 429-432.

18. Buzan T (1991) Use both sides of your brain. New mind-mapping techniques to help you raise all of your intelligence and creativity-based on the latest discoveries about the human brain. Plume Book, New York, USA.

19. Burnard $P$ (1991) A method of analysing interview transcripts in qualitative research. Nurse Educ Today 11: 461-466.
20. Whiting M, Sines D (2012) Mind maps: Establishing trustworthiness in qualitative research. Nurse Res 20: 21-27.

21. https://bubbl.us/

22. Lichstein PR (1990) The Medical Interview. In: H Kenneth Walker, W Dallas Hall, and J Willis Hurst, Clinical methods: The history, physical, and laboratory examinations. (3rd edn), Butterworths, Boston, UK.

23. Hollnagel $H$, Malterud $K$ (1995) Shifting attention from objective risk factors to patients' self-assessed health resources: A clinical model for general practice. Fam Pract 12: 423-429.

24. Reims KG, Ernst D (2016) Using motivational interviewing to promote healthy weight. Encouraging patients to talk about their goals rather than their obstacles can lead to long-term change. Fam Pract Manag 23: 32-38.

25. Steinmetz D, Tabenkin H (2001) The 'difficult patient' as perceived by family physicians. Fam Pract $18: 495-500$

26. Heritage J, Robinson JD, Elliott MN, Beckett M, Wilkes M (2007) Reducing patients' unmet concerns in primary care: The difference one word can make. $J$ Gen Intern Med 22: 1429-1433.

27. Dugdale DC, Epstein R, Pantilat SZ (1999) Time and the Patient-Physician Relationship. J Gen Intern Med 14: S34-S40.

28. Middleton JF, McKinley RK, Gillies CL (2006) Effect of patient completed agenda forms and doctors' education about the agenda on the outcome of consultations: Randomized controlled trial. BMJ 332: 1238

29. Harrison C, Henderson J, Miller G, Britt H (2017) The prevalence of diagnosed chronic conditions and multimorbidity in Australia: A method for estimating population prevalence from general practice patient encounter data. PLoS ONE 12: e0172935.

30. Epstein RM, Mauksch L, Carroll J, Jaén CR (2008) Have you really addressed your patient's concerns? Fam Pract Manag 15: 35-40.

31. Veldhuijzen W, Ram PM, Van der Weijden T, Niemantsverdriet S, Van de Vleuten CPN (2007) BMC Family Practice 8: 31

32. Ruiz-Moral R, Parras-Rejano JM, Alcalá-Partera JA, Castro-Martín E, Pérula de Torres LA (2005) Welcome and I'll see you again, or hello and goodbye? Communication behaviour of medical residents at the beginning and the end of consultations. Aten Primaria 36: 537-541.

33. Robinson JD (2001) Closing medical encounters: Two physician practices and their implications for the expression of patients' unstated concerns. Soc Sci Med 53: 639-656.

34. White J, Levinson W, Roter D (1994) “Oh, by the way ...”: the closing moments of the medical visit. J Gen Intern Med 9: 24-28.

35. Nielsen SB (2012) Patient initiated presentations of additional concerns. Discourse Stud 14: 549-565.

36. Turabian JL (1995) Notebooks of Family and Community Medicine. An introduction to the principles of Family Medicine. Diaz de Santos, Madrid, Spain.

37. Hart JT (1981) A new kind of doctor. J R Soc Med 74: 871-883

38. Hart JT (1988) A new kind of doctor. The General Practitioner's part in the health of the community. Merlin Press, London, UK.

39. Boshuizen HC, Poos MJJC, van den Akker M, van Boven K, Korevaar JC, et al. (2017) Estimating incidence and prevalence rates of chronic diseases using disease modeling. Popul Health Metr 15: 13.

40. Park Y (2013) Negotiating last-minute concerns in closing Korean medica encounters: The use of gaze, body and talk. Soc Sci Med 97: 176-91.

41. Neighbourg R (1991) The inner consultation. MTP press, Lancaster,UK 